\title{
O entre do meio: re-flexões sobre o conceito de intermedialidade
}

Maurício Liesen; Escola de Comunicações e Artes, Universidade de São Paulo, São Paulo, SP; E-mail: <mauricioliesen@usp.br>.

\begin{abstract}
Resumo
Este trabalho apresenta algumas considerações teóricofilosóficas sobre um aparentemente pleonasmo: o conceito de intermedialidade - do latim inter (entre) medium (meio). Tendo como base recentes discussões do cenário acadêmico alemão sobre uma filosofia dos media, este texto volta-se à intermedialidade como tradução ou transição em detrimento à sobreposição de suportes técnicos - recorrente desde que Dick Higgins, artista do Fluxus, cunhou na década de sessenta o termo intermedia para designar o encontro entre arte, meios eletrônicos e cultura pop. Inicialmente, os conceitos de medium e de medialidade são problematizados. Particularmente a partir da teoria negativa dos media delineada pelo filósofo alemão Dieter Mersch, pretende-se compor uma crítica aos idealismo e apriorismo mediais. A sua principal tese é a de que o medium sacrifica sua aparição no momento em que media. Ele não é produtor de sentido, de percepção ou de conhecimento, mas se co-media durante a mediação, alterando-a. Para torna-se visível, um medium precisaria, em princípio, de um outro medium. Por isso, a importância de se testar os limites do conceito de intermedialidade.
\end{abstract}

Palavras-chave: Intermedialidade, Medialidade, Filosofia dos Media, Teoria Negativa dos Media, Epistemologia da Comunicação.

I.

Em 1965, o artista do Fluxus Dick Higgins reivindicou pela primeira vez o uso da palavra intermedia, em um conhecido ensaio homônimo, para caracterizar certa produção de arte contemporânea que se expressava a partir da fusão conceitual (e não apenas sobreposição, como nos mixed media) de suportes heterodoxos - tais como aparelhos de TV, blocos de concreto, rádios, recortes de jornal, pintura, música e teatro. Como o próprio Higgins afirmou anos mais tarde, em 1981, apreendida como uma categoria a palavra intermedia seria capaz de facilitar a análise da obras artísticas que à época 
pareciam herméticas demais. A proposta atrás deste conceito era acima de tudo hermenêutica: ela respondia à necessidade de classificação e de explicação de objetos artísticos que escapavam às formas de arte já canonizadas - como a pintura, a escultura, a música e a literatura. Portanto, sob a definição de Higgins, o intemedium e sua forma plural intermedia definem obras que se encontram conceitualmente entre suportes conhecidos. Não por acaso, o artista do Fluxus reconhece o pioneirismo intermedial não apenas nos trabalhos de Marcel Duchamp, como também das fotocolagens de John Heartfield.

Ainda em seu conhecido artigo, como exemplos de trabalhos catalogados como intermediais, Higgins referiu-se particularmente às obras do alemão Wolf Vostell e dos artistas americanos Robert Rauschenberg e Allan Kaprow. A este último, considerado um dos pioneiros da performance, é atribuído o desenvolvimento do happening que, para Higgins, só pode ser concebido como um intermedium por excelência: "um território não cartografado que jaz entre a colagem, a música e o teatro e que não é regido por regras; cada trabalho determina seu próprio medium e sua própria forma de acordo com suas necessidades" (Higgins, 1984: 22). Por ser um conceito bastante abrangente, de certo modo autoexplicativo e em consonância com a proliferação dos meios técnicos digitais, as palavras intermedia e intermedialidade foram ganhando espaço não apenas no vocabulário especializado, mas também no cotidiano cada vez mais permeado pelas tecnologias informacionais.

É bem verdade que Dick Higgins reconheceu o pioneirismo do poeta inglês Samuel Taylor Coleridge no emprego do termo intermedium. Em 1812, Coleridge buscou descrever com esta palavra uma característica específica da narrativa alegórica (ela se distinguiria da mitologia por ser um intermedium entre pessoa e personificação, ou seja, aquilo que articula o geral com o particular). Contudo, ao propor o conceito de intermedialidade, Higgins ignorou a problemática inerente ao 
próprio conceito de medium que, por sua vez, possui uma longa carreira no pensamento ocidental. Para o artista do Fluxus, os media são entendidos como meros suportes técnicos para expressão artística.

O meu objetivo é apresentar uma outra abordagem do conceito de intermedialidade, que eu chamaria provisoriamente de conceito estético-filosófico, em detrimento ao conceito técnicoartístico utilizado por Higgins, que desconsidera a dimensão medial dos objetos artísticos.

Opto por utilizar o termo medium em detrimento a palavra mídia - e, consequentemente, $\mathrm{o}$ adjetivo medial e sua derivada substantivação, já que 0 adjetivo mediático refere-se expressamente ao termo mídia. Como se verá mais adiante, tal opção é justificada não apenas por conta do estranhamento provocado, mas porque a palavra medium aponta essencialmente para um outro fenômeno, mais próximo à teoria da percepção e à estética. $\mathrm{O}$ conceito de medium não caracteriza aqui um mercado empresarial, uma técnica, um aparato, o conjunto das formas de transmissão de informações e conhecimento, mas, sim, um modo, uma função ou uma estrutura que torna possível a aparição de algo e que, paradoxalmente, esconde suas formas no momento desta aparição.

II.

Antes mesmo de se tornar um termo técnico, a palavra latina intermedium já havia sido incorporada à língua portuguesa, como pode ser verificado nos seus primeiros dicionários, sob quatro formas de tradução: como entremédio, como entremeyo, como intermédio e como interméyo (Bluteau, 1716: 154 e 162). Todas designam algo que está no meio de duas coisas, no meio de dois extremos, mas também algo que está de permeio (Silva, 1813: 715). Composta pelos termos latinos inter e medium, a palavra intermeio parece constituir um pleonasmo: o entre do meio. 
Mas tal tautologia é apenas aparente, pois tomada como uma função de todo o medial, a intermedialidade é, grosso modo, a capacidade de observação de um medium a partir de um outro medium. Ela é a possibilidade de fuga a uma corrente que reafirma a impossibilidade de uma experiência i-mediata. Se tomarmos a afirmação do apriorismo medial como verdadeira a qual assume que tudo é resultado de um processo de mediação - como então mostrar a medialidade do medium, já que tal processo cairia na própria lógica do medial?

A intermedialidade é justamente a possibilidade de figuração de um medium a partir da exibição de suas fronteiras. Ela é o que acontece entre os media. Não são diferentes materiais que caracterizam a intermedialidade, nem o acréscimo de uma nova camada medial, mas a criação de uma nova medialidade.

Mas todas essas afirmações ainda carecem de mais detalhamentos, pois o próprio sentido de medium ainda não foi suficientemente abordado até aqui. Então antes de avançarmos com essa reflexão sobre o conceito de intermedialidade a partir de uma inspiração etimológica, é necessário um excurso sobre os conceitos de medium e medialidade.

III.

Como conceito, o termo medium é bem antigo e remete à teoria da percepção de Aristóteles (como desenvolvida no livro De Anima) e o conceito de metaxy, traduzido na Idade Média por Tomás de Aquino como medium (diaphanes). Introduzido como estrangeirismo em meados do século XVII na língua alemã, o termo foi largamente explorado pela filosofia de Kant, passando pelo Idealismo Alemão com Fichte, Schelling e Hegel, pela nascente filosofia da linguagem com Humboldt e Herder, até os escritos do início do século XX com Walter Benjamin e Theodor Adorno.

Tal tradição tem sido explorada na Alemanha pelas chamadas Ciências dos Media, o que possibilitou nas últimas duas 
décadas o surgimento nas universidades de um novo campo de estudos denominado Medienphilosophie [Filosofia dos Media]. De maneira bastante genérica, as correntes medialfilosóficas se dividem atualmente entre aquelas que se ocupam ou do primado do medial (o medium é o próprio sentido) ou da secundidade do medial (ele carrega um sentido que está em outro lugar, que não nele). Ou seja, ou o medium é visto ou como produtor ou como tradutor. Sobre a legitimação do termo dentro do cenário acadêmico trata-se, de um lado, de uma filosofia dos media em sentido estrito: o que os filósofos (na história da filosofia) têm a dizer sobre os media ou sobre o conceito de medium; por outro lado, trata-se de uma filosofia medial que busca trabalhar filosoficamente questões contemporâneas relacionadas aos media. No primeiro momento, uma releitura de momentos da filosofia de uma problematização não atentada ou não exaustivamente discutida; no segundo, um trabalho de elaboração conceitual para se pensar as novas relações mediais. Nela se inscrevem as revisões de todos os turns (linguistic, iconic, medial, performative etc) do último século.

Dentre as perspectivas do primado e da secundidade do medial, esta última ganhou força, ao ponto de propor um outro olhar sobre o fenômeno da medialidade mais próximo da estética e afastado dos estudos hermenêuticos, cujas pesquisas se voltam para o sentido. Para exemplificar este posicionamento, pode-se recorrer à diferenciação entre as perspectivas medial e sígnica das recentes teorias dos media, como proposta pela filósofa alemã Sybille Krämer, em seu livro Medium, Bote, Übertragung [Medium, Mensageiro, Transmissão], publicado em 2008. Krämer aponta para duas abordagens: uma voltada para $o$ que é transmitido signicamente e outra para o que é traduzido medialmente: "Na perspectiva semiológica, o 'oculto' do sentido está atrás do sensual; na perspectiva mediológica, ao contrário, o 'oculto' da sensação está atrás do sentido" (Krämer, 2008: 34). Em outras palavras, o signo deve ser perceptível, mas o que nele é 
perceptível, é secundário: o significado é que é importante, ou seja, aquilo que é tomado costumeiramente por ausente, invisível, ou até mesmo imaterial. O signo é em geral concebido como algo que está para uma outra coisa, que indica algo além de sua materialidade. O medium, por sua vez, funciona justamente ao contrário: o que nós percebemos é a própria mensagem, que surge no acontecimento medial. $\mathrm{O}$ medium é o secundário: ele se neutraliza, se recolhe no seu uso. Ao contrário da relação sígnica, que atrás do sensório encontra-se o sentido, a perspectiva medial propõe que atrás da mensagem visível se esconde o medium invisível (Krämer, 2008: 35). Tal concepção do medium como algo que se esconde no momento da sua manifestação é desenvolvida extensivamente pela obra do filósofo Dieter Mersch, cuja proposta culmina em uma teoria negativa dos media. Para Mersch, os media possuem a capacidade de esconder sua medialidade na medida em que ela ocorre: "Sua presença tem o formato de uma ausência" (Mersch, 2008: 304). A estrutura do medial, portanto, não pode ser mediada. Ela se mostra. $O$ que é passível de observação não é o medium, mas a sua aparição fenomênica como medialidade, pois o medium é algo que torna alguma coisa presente, mas que não se deixa apreender neste processo. Ele não pode ser tematizado. Daí a sua negatividade.

IV.

A teoria negativa dos media proposta por Dieter Mersch pode ser considerada como uma crítica - ou uma saída - ao apriorismo medial que inundou às ciências humanas nas últimas décadas. Entender o medium como um a priori significa dizer que não existe um fora do medium, já que toda forma de conhecimento e reconhecimento seriam mediadas (por signos). Ou seja, a partir desta visão se instaurou um topos comum nas humanidades que reverbera a certeza de que o real é um efeito dos media, de que os media constroem realidades, produzem conhecimento, representam pensamentos, guardam memórias, 
possibilitam a ação e a comunicação, em suma, uma atitude teórica que reverbera a máxima de que os media são as condições de possibilidade de toda experiência'.

Assim, tal visão - que estrutura a nossa relação com o mundo como uma relação mediada - incorre em uma espécie de idealismo medial, em uma totalização que fica paralisada diante da questão de como o medium poderia ser reconhecido, já que tudo seria seu produto: como a medialidade poderia ser percebida, localizada ou compreendida? Como experenciar algo medial dentro do próprio medial?

Mersch reconhece que o pensamento e a produção de sentidos não podem existir sem os media, mas - e esse é o ponto crucial de sua argumentação - isso não quer dizer que os media são os produtores destes sentidos. Os media tornam algo audível, visualizável, sensível, eles organizam, retêm, transportam, transformam, mas não criam significados: eles os pressupõem. "Não existe nenhum simbólico, nenhuma percepção livre dos media - mas nenhum medium é jamais o doador do seu acontecimento" (Mersch, 2004: 77).

Além deste aspecto imaterial ou operacional, o filósofo ressalta a inseparabilidade da dimensão material do medium, já que eles também são, sempre, alguma coisa, sejam arquivos, imagens, aparatos técnicos etc ${ }^{2}$. Por isso, mesmo que transparente, a medialidade não brota metafisicamente das

1 Tal transcendentalidade e ubiquidade do medium também foi consistentemente abordada e criticada na obra da filósofa Sybille Krämer $(1998,2003)$.

2 A questão da materialidade do signo vai ser explorada extensivamente por Mersch em sua obra Was sich zeigt: Materialität, Präsez, Ereignis, particularmente na segunda parte, intitulada Os signos e seu outro [Die Zeichen und ihr Anderes]: Cf. Mersch, 2002: 131-355. 
funções do medium. Essa certa transparência da medialidade ${ }^{3}$ é inspirada na concepção de medium da estética aristotélica exposta no livro Sobre a Alma, mais precisamente na sétima parte do segundo livro, intitulada "A sensibilidade: $A$ visão e o seu objeto" (Aristóteles, 2010: 80 ss.). Para o filósofo grego, o diáfano 4 é aquilo que possibilita a percepção. $O$ transparente atua como o contraponto do $\mu \varepsilon т a \xi u$ (metaxy), ou seja, daquele vazio que está no meio (entre) o órgão sensorial e o objeto.

Para Dieter Mersch, o diáfano pode fornecer um outro modelo para compreensão do medial, considerado portanto como algo - material - que possibilita o aparecer. Não é o material que é transparente, mas o próprio aparecer como trans-parente, na medida em que algo através disso se faz visível. O diáfano surge como o lugar próprio da visualização: algo que mostra, mas que ao mesmo tempo se recolhe.

Para explicitar essa impossibilidade de definição do medium e responder ao problema da tematização do medial no próprio medial, Mersch recorreu à filosofia da linguagem de Ludwig Wittgenstein, Martin Heidegger e Jacques Derrida.

V.

O ensaio Sobre verdade e mentira no sentido extramoral [Über Wahrheit und Lüge im außermoralischen Sinne] escrito em 1873 (mas só publicado postumamente) pelo filósofo alemão Friedrich Nietzsche é um texto fundamental não apenas por ajudar a compreender o perspectivismo filosófico nietzscheano, mas particularmente por apresentar a problemática que iria dominar não apenas a filosofia da linguagem do século $X X$

3 Outro filósofo que explora a característica da transparência do medial, mas sob uma perspectiva fenomenológica, é o professor da Universidade de Jena, Lambert Wiesing, Cf. Wiesing, 2005.

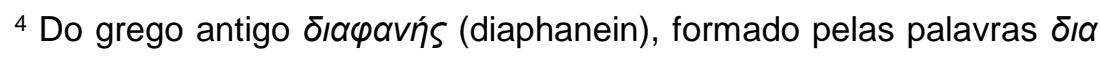

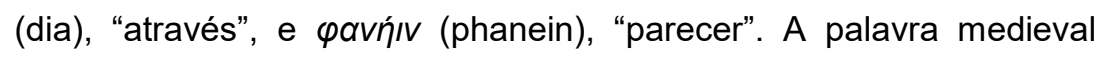
latina transparente- guarda este mesmo sentido. 
como praticamente todas as ciências humanas: a nossa relação com o mundo é, acima de tudo, mediada pelo discurso.

De acordo com Nietzsche, a figura que melhor representa a linguagem é a metáfora. Todo homem, portanto, seria um artista, pois necessita da criação de metáforas para compor sua relação com o mundo. Em seu ensaio, a linguagem é denunciada como uma prisão, cujo esquecimento da metáfora original seria o único motivo que ainda nos empurraria em direção à verdade. Pela linguagem, o homem se afasta dos objetos. Por esse motivo, a relação estética com o mundo seria a única possível: "Entre duas esferas absolutamente diferentes, como o sujeito e o objeto, não há nenhuma causalidade, nenhuma exatidão, nenhuma expressão, mas, no máximo, um comportamento estético, quero dizer, uma transmissão alusiva, uma tradução gaguejante em uma língua completamente estrangeira" (Nietzsche, 2000: 19-20).

Mas um problema então permanece como um espinho encravado na pele da filosofia da linguagem ou, mutatis mutandis, de uma filosofia dos media: como então tematizar a linguagem quando todo falar sobre ela já é, ele próprio, linguagem?

O filósofo austríaco Ludwig Wittgenstein em sua primeira grande obra, o Tractatus Logico-Philosophicus, publicada em 1922, extrai o cerne desta questão ao delimitar que onde cessa o dizer, entra a dimensão do mostrar. Acima de tudo, o dizer e o mostrar são dois regimes intraduzíveis. A forma lógica da imagem e da linguagem sempre buscam se exibir de forma diferente, como expresso em duas passagens: "Sua forma de afiguração, contudo, a figuração não pode afigurar; apenas a exibe" (Wittgenstein, 1968: 2.172); e "A proposição não pode representar a forma lógica, esta espelha-se naquela. Não é possível representar o que se espelha na linguagem. $O$ que se exprime na linguagem não podemos expressar por meio dela. A proposição mostra a forma lógica da realidade. Ela a exibe" (ibid.: 4.121). 
A partir dessas categorias, Mersch agrupa os media em modos discursivos (a palavra e os números) e os estésicos (o som e a imagem) que se desdobram como dimensões irredutíveis, ou seja, que não podem ser convertidas entre $\mathrm{si}^{5}$, mesmo que exista a possibilidade de transcrição em outro suporte. Por exemplo, no caso da música, que pode ser escrita como partitura musical, permanece sempre a diferença entre a percepção e a aparição, de um lado, e a textualidade e o discurso de outro. Um dos trabalhos de uma teoria dos media seria o de delimitar a incompatibilidade entre os media, na contramão da dinâmica de totalização presente em boa parte do discurso teórico em prol de uma intermedialização numérica absoluta. A diferença entre a aisthesis e o discursivo assinala a pluralidade dos media de acordo com o dizer e o mostrar nos moldes de Wittgenstein: "O que pode ser mostrado, não pode ser dito" (Wittgenstein, 1995: 34 [4.1212]). Esses dois aspectos estão presentes em todos os formatos mediais, mas um deles rege o medium. "Media discursivos mostram - onde eles mostram - no modo do dizer, enquanto media estésicos - onde eles dizem - falam no modo do mostrar" (Mersch, 2004: 85).

Mesmo diferentes, as dimensões do dizer e do mostrar são colaterais, ou seja, uma não existe sem a outra. A partir do pensamento de Wittgenstein, o que se expõe é a característica da linguagem como acontecimento que se mostra ao falar. Não por acaso sua filosofia fundamenta a teoria performativa dos atos de fala (Austin, 1975).

Essa relação entre o mostrar e o dizer constitui uma estrutura quiasmática na qual permite a co-existência de dois contrários no processo de medialidade, a saber, a simultaneidade da distância e da proximidade, da ausência e da presença. Esse caráter de acontecimentalidade atingiria toda forma de comunicação. Por exemplo, a percepção de uma imagem, na

${ }^{5}$ Para um aprofundamento desses quatro modelos mediais básicos (palavra, número, som e imagem) na obra de Dieter Mersch, cf. Mersch, 2003. 
qual o processo de medialidade acontece a partir de uma dupla diferença: "Primeiro, por uma impossibilidade de mediatização do ponto sedutor do olhar e, segundo, pela impossibilidade de encenação da consumação comunicativa que pode acontecer por si só” (Mersch, 2004: 87).

Como Mersch resume, a partir da filosofia primeira de Wittgenstein os aspectos mediais da linguagem podem ser exibidos pela lógica negativa do recolhimento: "'a linguagem se nega tanto à sua reflexão quanto a sua totalização. O linguístico [Sprachlichkeit] da linguagem permanece, com isso um mistério permanente" (Mersch, 2002: 253).

Como pensar esse mistério da linguagem foi o objeto das investigações linguísticas do filósofo alemão Martin Heidegger ( ${ }^{* 1889}$ †1976), exibidas em ensaios escritos entre 1950 e 1959 e reunidos no livro Unterwegs zur Sprache $[\hat{A}$ caminho da linguagem]. Heidegger escreve sobre a necessidade de arruar um caminho pela linguagem até a linguagem, ou melhor, para trazer a linguagem para a linguagem e exibir sua essência (seu movimento) acontecimental, como expressa na sua fórmula: "Trazer a linguagem como linguagem para a linguagem" (Heidegger, 1985: 242 et passim). Como o ser humano habita a linguagem, todo falar sobre a linguagem já está enredado em um dizer (ibid.: 161). Portanto, é necessário se ter uma experiência com a linguagem para exibir, de forma indireta, sua medialidade. Como descrito anteriormente, o significado heideggeriano de experiência carrega o verbo alemão widerfahren, de difícil tradução ao português, já que ele guarda um sentido passivo de "ser atingido por algo que acontece", por algo que não se tem qualquer controle.

Como, então, a linguagem se revelaria como linguagem? "A linguagem fala [Die Sprache spricht]. O ser humano fala, na medida em que ele corresponde à linguagem" (ibid.: 33). Isso significa que a essência da linguagem é a linguagem da essência, já que não falamos a linguagem como também falamos dela. "Por isso, a filosofia da linguagem não consegue 
encontrar a linguagem - tampouco uma filosofia dos media os próprios media -, mas tão somente 'sulcamentos' ou rastros de tal modificação" (Mersch, 2013: 211). Para caminhar à linguagem é necessário uma escuta: escutar o falar linguagem. Percebê-la em movimento a partir dos seus rastros, seus sulcos [Furchen], onde manifesta-se sua "rasgadura" [Aufriss]: "a linguagem fala no momento em que ela diz, ou seja, mostra" (Heidegger, 1985: 255). Para Heidegger, esse momento em que a linguagem se mostra pode ser revelado no recolhimento à linguagem (em contraponto ao isolamento) e, particularmente, na poesia. No momento em que acontece, a linguagem concede, em sua essência, a morada aos mortais. "O movimento [Be-wägung] traz a linguagem (o ser da linguagem) como linguagem (a saga) para a linguagem (para a palavra falada)" (ibid.: 262). A saga é justamente o caráter acontecimental da linguagem, que se mostra. Como ressalta Dieter Mersch, tanto Heidegger quanto Wittgenstein usam a mesma palavra para apresentar a linguagem para além de uma ferramenta simbólica, a saber, o "mostrante" [Zeige]: "O 'mostrante' é aquilo que no processo do falar, isto é, na performatividade da fala, consegue apenas mostrar-se ou revelar-se. E o que se manifesta ou se mostra não pode ser pronunciado. Ele se nega a uma possibilidade de definição adequada" (Mersch, 2013, p. 212).

A instauração de um novo vocabulário e do trabalho nas margens do medium são necessários para exibir o medium que se nega a qualquer definição. $O$ medium emerge como aquilo que com-forma, mas que sacrifica suas formas. Para Dieter Mersch, a medialidade se mostra "como aquela indefinibilidade da qual apenas novos esboços podem ser feitos e cujos riscos e rasgaduras provêm principalmente de performatividades e interrupções transversais, que chegam indiretamente e se agarram às estruturas, criando rachaduras e contradições, para combater o paradoxo do medial" (Mersch, 2013: 212). 
É a partir da possibilidade de manifestação da estruturalidade da linguagem com Wittgenstein e Heidegger que se delineia uma teoria negativa dos media, cujo objetivo é revelar os traços do medial que obstinadamente desaparecem na aparição, que se sacrificam na perfeição técnica, mas que permanecem como a presença de uma ausência.

VI.

A partir do que foi exposto, podemos visualizar três bloqueios mediais denunciados por Mersch em sua teoria negativa: ao bloqueios da materialidade (indisponibilidade de apreensão de todos os aspectos do medium), das diferenças (inescrutabilidade entre a palavra, a imagem, o som e o algarismo) e da autorrealização do medial (seu caráter acontecimental). "Essas três barreiras correspondem às três impossibilidades primordiais de representação: recolhimento da medialidade do medium, limites de possibilidade de conversão mútua e impossibilidade de definição do lugar de onde a mediatização ocorre" (Mersch, 2004: 90).

O conceito de medium recusa-se a qualquer explicação teórica estrita. Ele encerra qualquer possibilidade de explicação discursiva. Daí o caráter indireto de sua natureza. Ele se manifesta apenas na sua performance, ou seja, no momento de sua execução.

A materialidade do medium é a fronteira na qual se estruturam as condições mediais. Todo medium dispõe de algo finito, concreto, que limita sua execução. É justamente pela materialidade - a ex-sistência do medium - que ele deixa seus rastros. É no momento de sua deterioração, que a medialidade se torna aparente. É na palavra rasurada, no disco arranhado, na tela travada, nos retardamentos, no filme mofado, no ruído, na pertubação da atenção, na cor desbotada, no bug, no pixel estourado, no controle emperrado etc. que a perfectio medial entra em crise. E esse momento é o que eu chamo aqui de 0 entre do meio ou intermedialidade. 
A efetivação de um medium está diretamente relacionada à criação da ilusão de uma amedialidade. Quanto mais os media e suas medialidades passam despercebidos, mais efetivos eles são. A teleologia da técnica é a manutenção do mistério medial, ou seja, em garantir sua impenetrabilidade que sustenta o ilusionismo do a priori medial. Por este motivo, os efeitos sempre foram os elementos mais ponderados do processo de medialidade, já que aquilo que está "no meio" tende a ser ignorado. $\mathrm{Na}$ imaterialização de sua materialidade o medium cumpre sua função. Mas até em processos de medialidade bem sucedidos existem elementos que logram ilusão de amedialidade.

Como vimos, algo sempre excede às estruturas de medialidade. Mas é o próprio excesso que permite a reflexão do medial. É o excesso marcado pelo pleonasmo do conceito de intermedialidade. O que está entre o "entre" difuso do medial? Ou como exibi-lo sem ficar enredado em sua própria lógica?

Ponderada a partir os aspectos discutidos neste trabalho, a teoria dos media encontra-se diante de um dos grandes problemas da estética: o essencialismo, que busca particularidades e irredutibilidades de cada forma de expressão. Tal intricamento já havia sido percebido pelo poeta alemão Gotthold Ephraim Lessing, que em sua obra Laocoonte, de 1836, buscou definir os mecanismos de efeito específicos da pintura e da poesia a partir se suas estruturas mediais específicas. Lessing afirmou a independência da imagem em relação à linguagem e uma intraduzibilidade e intransponibilidade entre media. Tal posição influenciou o surgimento da estética como disciplina filosófica, com Baumgarten e depois o reconhecimento da autonomia do conhecimento estético por Immanuel Kant.

Por atuar nos limites das materialidades e das funcionalidades do medial, a arte emerge como um lugar privilegiado para apreensão do medium como medium. Ela possui uma função 
intermedial por excelência, pois ao explorar os limites de um medium, a arte expõe algo que está no entre e não mais no medial (Mersch, 2004: 93). Uma teoria dos media que atenta para a lógica negativa da medialidade deve permanecer persistentemente nesta fronteira do recolhimento estrutural do medium.

A intermedialidade atua na intransitividade do medium, na sua impossibilidade de representação. Essa intransitividade marca a própria possibilidade de tradução de um medium em outro, e é neste espaço amorfo, neste entre, que atua a intermedialidade. Traduzir, por sua vez, não significa relacionar um simbólico ao outro, no campo da representação e da significação, como uma transferência de sentido, mas é a revelação das estruturas mediais. Como toda tradução é uma distorção, tais estruturas só podem ser apreendidas lateralmente, de forma indireta: intermedial.

\section{Referências}

Aristóteles. (2010). Sobre a alma. (A. M. Lóio, Trans.). Lisboa: Imprensa Nacional-Casa da moeda.

Austin, J. L. (1975). How to Do Things with Words. Cambridge: Harvard University Press.

Bluteau, R. (1716). Vocabulario Portuguez E Latino: L-N [Vol. 5]. Coimbra: Collegio das Artes da Companhia de Jesus.

Derrida, J. (1991). Margens da Filosofia. (J. T. Costa \& A. M. Magalhães, Trans.). Campinas: Papirus.

Heidegger, M. (1985). Unterwegs zur Sprache - Gesamtausgabe I. Abteilung: Veröffentlichte Schriften 1910-1976 (Vol. 12). Frankfurt am Main: Vittorio Klostermann.

Higgins, D. (1984). Horizons: The Poetics and Theory of the Intermedia. Carbondale: Southern Illinois University Press.

Krämer, S. (1998). Das Medium als Spur und als Apparat. In S. Krämer (Ed.), Medien Computer Realität: Wirklichkeitsvorstellungen und Neue Medien (pp. 73-94). Frankfurt am Main: Suhrkamp Verlag. 
Krämer, S. (2003). Erfüllen Medien eine Konstitutionsleistung? Thesen über die Rolle medientheoretischer Erwägung beim Philosophieren. In S. Münker, A. Roesler, \& M. Sandbothe (Eds.), Medienphilosophie. Beiträge zur Klärung eines Begriffs (pp. 78-90). Frankfurt am Main: Fischer Taschenbuch Verlag.

Krämer, S. (2008). Medium, Bote, Übertragung: kleine Metaphysik der Medialität. Frankfurt am Main: Suhrkamp Verlag.

Mersch, D. (2002). Was sich zeigt. Materialität, Präsenz, Ereignis. München: Fink.

Mersch, D. (2003). Wort, Bild, Ton, Zahl: Modalitäten medialen Darstellens. In D. Mersch (Ed.), Die Medien der Künste: Beiträge zur Theorie des Darstellens (pp. 9-49). München: Wilhelm Fink Verlag.

Mersch, D. (2004). Medialität und Undarstellbarkeit. Einleitung in eine "negative" Medientheorie. In S. Krämer (Ed.), Performativitat und Medialität (pp. 75-96). München-Paderborn: Wilhelm Fink.

Mersch, D. (2008). Tertium datur: Einleitung in eine negative Medientheorie. In In: MÜNKER, Stefan \& ROESLER, Alexander (orgs.). Was ist ein Medium? Frankfurt am Main: Suhrkamp Verlag.

Mersch, D. (2013). Tertium datur: introdução a uma teoria negativa dos media. (M. Liesen, Trans.). Revista Matrizes, 7(1), 207-222. Retrieved from http://www.matrizes.usp.br/index.php/matrizes/article/view/353

Nietzsche, F. (2000). Über Wahrheit und Lüge: Ein Essay, Aphorismen und Briefe. (S. Dietzsch, Ed.). Frankfurt am Main: Insel Verlag.

Silva, A. M. (1813). Diccionario da lingua portugueza - recompilado dos vocabularios impressos ate agora, e nesta segunda edição novamente emendado e muito acrescentado, por ANTONIO DE MORAES SILVA. Lisboa: Typographia Lacerdina. Retrieved from http://www.brasiliana.usp.br/bbd/handle/1918/00299210

Wiesing, L. (2005). Artifizielle Präsenz. Frankfurt am Main: Suhrkamp Verlag.

Wittgenstein, L. (1968). Tratactus logico-philosophicus. (J. A. Giannotti, Trans.). São Paulo: Edusp.

Wittgenstein, L. (1995). Werkausgabe in 8 Bänden - Band 1: Tractatus logico-philosophicus. Tagebücher 1914-1916. 
Philosophische Untersuchungen (10th ed., p. 620). Frankfurt am Main: Suhrkamp Verlag. 